\title{
Realization in biology?
}

\author{
Sergio Balari ${ }^{1}$ (D) Guillermo Lorenzo $^{2}$ (D)
}

Received: 29 August 2018 / Accepted: 18 February 2019 / Published online: 25 February 2019 (C) The Author(s) 2019

\begin{abstract}
It is widely assumed that functional and dispositional properties are not identical to their physical base, but that there is some kind of asymmetrical ontological dependence between them. In this regard, a popular idea is that the former are realized by the latter, which, under the non-identity assumption, is generally understood to be a non-causal, constitutive relation. In this paper we examine two of the most widely accepted approaches to realization, the so-called 'flat view' and the 'dimensioned view', and we analyze their explanatory relevance in the light of a number of examples from the life sciences, paying special attention to developmental phenomena. Our conclusion is that the emphasis placed by modern-day biology on such properties as variability, evolvability, and a whole collection of phenomena like modularity, robustness, and developmental constraint or developmental bias requires the adoption of a much more dynamic perspective than traditional realization frameworks are able to capture.
\end{abstract}

Keywords Realization · Functions · Disposition · Organic activity · Cognition · Eco-evo-devo biology

Sergio Balari

Sergi.Balari@uab.cat

1 Departament de Filologia Catalana and Centre de Lingüística Teòrica, Facultat de Filosofia i Lletres, Edifici B, Universitat Autònoma de Barcelona, 08193 Bellaterra, Barcelona, Spain

2 Departamento de Filología Española - Lingüística General, Facultad de Filosofía y Letras, Universidad de Oviedo, 33011 Oviedo, Spain 


\section{Introduction}

Understood as a philosophical term of art, 'realization' denotes a relationship between kinds of entities. The nature, status and number of such entities in a particular realization relationship depends on the particular definition of realization one wants to endorse, as-alas - there is more than one such definition (Baysan 2015; Wilson and Craver 2007). This polysemy notwithstanding, it is perhaps not too inaccurate to affirm that all conceptions of realization share certain common features, in particular, the idea that realization always involves some form of ontological dependence between the realized entities and their realizers. To put it succinctly, realization is the route through which a specific kind of entity (the realized one) acquires ontological respectability (or "physical legitimacy;" Polger and Shapiro 2016: 21) by virtue of being related to its realizer-or realizers, since it is possible that realizer entities may outnumber realized ones. Therefore, realization may be one-to-one, but it may also be one-to-many. For the purposes of this introductory section, this brief and, we submit, perhaps imprecise characterization should nonetheless suffice to appreciate that realization, however it is defined and insofar as it is a relation, always involves at least two entities, the realizer and the realized.

Crucially, realization is not — cannot be-identity, where the latter must be understood in the sense that if $a$ and $b$ are identical then $a$ and $b$ are one and the same entity, not simply two entities that happen to be alike. Indeed, realization was originally put forth as a knock down argument against the contention that minds are identical to brains, submitting that psychological kinds are not identical to neurophysiological kinds but, rather, are merely realized by them. Non-identity would follow from the (purportedly empirical) fact that the very same psychological kind may be realized differently in different organisms or even in the same organism at different times, which conforms the Multiple Realizability (MR) argument against the identity thesis; see Bickle (2016) and the references cited therein for a historical sketch.

Hilary Putnam, the original perpetrator of the argument, presented MR as an empirical hypothesis (Putnam 1975c: 433), ${ }^{1}$ indeed as a more plausible hypothesis than its rival the identity thesis. Until recently, the empirical validity of MR has hardly ever been questioned and, in fact, it has basically been assumed on the grounds of vague references to convergent evolution and the (presumed) sheer implausibility that two creatures sharing certain aspects of their psychology may also share the underlying physical structures over which their respective psychologies rest (Block and Fodor 1972, for an example of this). Lack of empirical confirmation has not anyhow been an obstacle for philosophers to brandish MR in their debates about the status of reduction in connection with the special sciences; indeed, it appears that MR is the pillar on which the autonomy of special sciences rests make it collapse and the whole edifice of the autonomy of the special sciences will be reduced to rubble.

\footnotetext{
1 All references to Putnam's works are to their reprints in his Philosophical Papers; accordingly, page numbers correspond to the said volumes.
} 
We are not sure that the question of reduction is so central nowadays (if it ever was), and we tend to align with Chomsky's conception of naturalism in these matters (especially, Chomsky 2000: ch. 4), where the idea of reduction makes little sense. This is, in any case, a relatively ancillary issue into which we will not enter, but the question of the empirical adequacy of MR still lingers and it is to this topic that the core of this paper will be devoted. In reality, more than MR our target is 'realization' itself and the importance (or lack thereof) which this notion may have for the biological sciences, with special reference to that branch of biology to which it was first applied, namely the cognitive and brain sciences. In a nutshell, we will contend that realization has only little (if any) epistemic (or heuristic) value in biological theorizing and practice, a conclusion which casts serious doubts over its ultimate ontic value. Our conclusion will be based on a number of intricately interwoven observations concerning certain features which, to a greater or lesser extent, may be considered to be common to current mainstream realizationist approaches and which can be summarized by the following four points: (1) The problem of levels of analysis; (2) the problem of synchronicity; (3) the problem of explanation; and (4) the problem of identity. Thus, in the next section (Sect. 2), we present a brief examination of the genesis of the technical notion of 'realization' and of its quasisynonym 'implementation' as it is understood in computing in order to show that this common origin has resulted in a confusion between levels of realization and levels of mechanisms, a confusion which, in our opinion, pervades all approaches to realization. In Sect. 3, we turn to what is generally known as the 'flat view' of realization in order to assess its explanatory force by confronting it with a couple of examples from developmental biology. Our focus here, in addition to the problem of explanation, will be the problem of synchronicity. Section 4 analyzes the 'dimensioned view' on realization. There, we return to the question of levels and, in this context, we introduce the problem of identity in connection with the notion of MR and the notion of biological homology. Finally, we turn to the problem of synchronicity in connection, in this case, with an example taken from language processing. The paper closes with some reflections on the fate of realization in the context of contemporary debates in the life sciences.

\section{Realization and levels of analysis}

In order to assess the (metaphysical/epistemic) value of realization, it becomes inevitable to take into account the (metaphysical/epistemic) work that the notion is presumed to be doing in the context in which it is invoked. As we noted in the introduction, realization is a polysemous term and this is partly due to the fact that it has been summoned in different situations and for different purposes. The first documented textual evidence of the term 'realization' used in a quasi-technical sense is in Hilary Putnam's 1960 paper 'Minds and Machines' (Kim 2010; Putnam 1975a). The MR argument is constructed in two steps, corresponding respectively to two papers published in 1967, namely 'The mental life of some machines' (Putnam 1975b) and 'Psychological predicates' (reprinted as 'The nature of mental states;' Putnam 1975c): 
(1) In a first paper (Putnam 1975a), after having asserted that "the mind-body problem is strictly analogous to the problem of the relation between structural and logical states" (Putnam 1975a: 383; emphasis in the original), Putnam concludes that, as matter of pure logic, one cannot deduce the machine table of an implemented device from its physical-chemical description, precisely because any Turing Machine can be realized in many different ways.

(2) In a later paper (Putnam 1975c: 436-437), Putnam famously turns this argument into the empirical thesis that it is highly implausible that the same functional state be realized by exactly the same physical-chemical correlate in different creatures. This, as aptly characterized by Shapiro (2004: 23-27), possesses the form of a likelihood argument.

Therefore, the collection of assumptions on which the idea of realization rests can be spelled out as follows:

(a) Organisms are strictly analogous to machines.

(b) Machines can be functionally individuated and, accordingly, one can elaborate an abstract, functional description of any machine.

(c) From the functional description of a machine, one can construct (implement, realize, instantiate) a variety of physical entities capable of performing exactly the same function despite their possibly many differences in construction (implementation, realization, instantiation).

(d) The study and analysis of organisms can be carried out in exactly the same terms as the study and analysis of machines.

Note, in particular, that from (d) it follows that organisms or parts thereof realize (implement, instantiate) particular functions. This probably explains why many philosophers have seen in the idea of realization the final solution in which physicalism can be grounded (e.g. Boyd 1980; Poland 1994; Kim 1998, 2005; Melnyk 2003; Shoemaker 2007). This, however, constitutes a ramification of the issue of realization into which we will not enter here.

Our main point of concern will be that, in spite of the many revisions, formulations and reformulations of realization as a technical notion, the assumptions (a)-(d) above have never been challenged. Functionalism and its accomplice notion of realization are based on a metaphor and, we surmise, a very bad metaphor at that, the demise of which, we fear, neither one nor the other will survive. This is not, however, the only problem with the metaphor, though, because in the organism-machine analogy is also implicit some idea of 'levels of analysis.' As we will see, the question of levels has also played an important role in discussions of realization, especially because of the more or less explicit association most philosophers establish between realization and reduction.

We suspect that the source of this conflation is Jerry Fodor and his manytimes-reproduced line-drawing representing the relation between special sciences and reducing sciences (Fodor 1974: 109, 1975: 20), where attempts to dovetail his account of phase-one psychological theories (Fodor 1965, 1968: 107-111) 
with Putnam's machine-functionalism and with the MR argument against the reduction of psychology to neuroscience (or physics). The topology of Fodor's sketch suggests a top-down relation, which appears to agree with Oppenheim and Putnam's (1958) conception of 'levels,' and which encourages blending the idea of 'levels' of mechanisms (Fodor's proposal for psychological explanation) with the idea of 'levels' of realization (Putnam's proposal to escape reduction); Craver (2007: chs. 5-6) for a detailed analysis of this difference. The problem here is that Fodor identified his phase-one theories (the theory of what the circuitry does) with Putnam's functional level of description of the machine (what may eventually be implemented), but this identification is not possible. The difficulty lies in the notion of implementation (or realization). The standard meaning of implementation' in computer science is that of going from something abstract to something more concrete or less abstract, which, in our reading, matches Putnam's original characterization. Thus, in computer science, the implementation relation connects different levels of abstraction (Aho et al. 1983; Patterson and Hennessy 2017), where a higher level is related to the level immediately below it by a relation of representation (Winograd and Flores 1986), not a relation of constitution, which, as we will see, is what it is usually meant by realization. Therefore, the implementation relation in computer science is a semantic one, where the different levels of abstraction simply represent (some specific aspect of) the only thing there is: the physical machine. Abstraction in computer science is merely a tool, albeit a very useful one, to facilitate the task of building and programming computers. It is no wonder that computer scientists have few (if any) commitments as to the ontological status of programs or algorithms: they are helpful abstractions (representations), perhaps just like mathematics is the indispensable tool for physicists to model reality (Ladyman et al. 2007: 159ff, for discussion). Despite being inclined to endorse the ascription of this instrumental role to computer science as a tool for building models in cognitive science research, we suspect that this may seriously undermine the metaphysical status of realization (Klein 2008, 2013, for a similar contention). These considerations notwithstanding, for the sake of the argument we propose accepting the original conceptual basis and pose the following question: From the perspective of the life sciences, what is the current status of both functionalism and realization given their current formulation? This is the query we will try to answer in the following sections by taking a closer look at two current approaches to the metaphysics of realization generally known as 'the flat view' and 'the dimensioned view,' championed, respectively, by Thomas Polger and Lawrence Shapiro, and Kenneth Aizawa and Carl Gillett.

\section{The flat view}

There are different approaches to realization that fall more or less under the label 'flat view,' but we will focus on one that has been explored by Thomas Polger and Lawrence Shapiro in a number of publications (Shapiro 2000, 2004; Polger 2004) and that has its most stable version to date in Polger and Shapiro (2016). Their 
definition of flat realization $\left(\mathrm{R}_{\mathrm{F}}\right)$ is this (Polger 2007: 251; Polger and Shapiro 2016: 22):

$\left(R_{F}\right) \quad$ Necessarily, $P$ realizes $G$ if and only if $P$ has the function $F_{G}$

Consequently, realization is tantamount to having a function. Polger and Shapiro rely heavily on the organism-machine metaphor in their writings - indeed, their main conclusions are drawn from an imaginary science of corkscrews and are later extrapolated to the case of the relation between mental states and brain states. We believe that this strategy is problematic, indeed quite damaging for the whole edifice of $\mathrm{R}_{\mathrm{F}}$. In the following we try to show why.

According to the detailed approximation offered by the authors in Chapter 2 of their book, realization entails the following definitional traits (see also Shapiro 2004; Polger 2007):

(a) Ontological dependence-the existence of a given mental state depends on the existence of some physical realizer.

(b) Synchronicity - a mental state persists as long as its physical realizer remains active.

(c) Non-destructiveness - a physical state needs to maintain its integrity so as to allow habitual repetitions of the same mental state.

(d) Non-causality - mental states 'supervene' on physical states, which is different from being caused by them.

(e) Multiplicity - one particular mental state is not restricted to only supervening on one particular kind of realizer.

Obviously, although the traits above are defined with reference to mental states, they can be generalized to allow their application in other areas as well. Indeed, the authors themselves recognize that their definition is not particularly committed to one particular definition of function and that it can therefore be accommodated to whatever notion of 'having a function' one may be inclined to support (Polger and Shapiro 2016: 23). In spite of their self-proclaimed agnosticism regarding functions, however, the proposed framework may be better suited to certain definitions of function than others. In fact, Shapiro explicitly appeals to Cummins-functions (Cummins 1975, 1983) as the kinds of functions that are realized (Shapiro 2004: 44ff). He explains that this is simply a matter of convenience, insinuating that choice of the kind of function does not impinge on the question of realization (and MR). We harbor certain doubts as to the validity of this last statement and, in fact, we believe that Shapiro's choice of the kind of function, whether deliberate or not, is the most appropriate one for the flat view. For two reasons.

The first reason is that Cummins-functions are those 'causal role' functions traditionally invoked in the kinds of mechanistic explanations defended by Fodor (1965, 1968) and Cummins (1983) himself and, more recently, by the so-called 'new mechanical philosophers' working in the wake of Machamer et al. (2000) 
-e.g. Craver (2001) and Piccinini and Craver (2011). Thus, Cummins-functions fit well with the causal profiles of the realizers when seen as entities that are part of a mechanism and when asking questions of the 'how does it work' kind (Cummins 2002). Indeed, Shapiro (2004: 46), when discussing the issue of functions, explicitly states that "when I talk of functional kinds I shall have in mind kinds defined by some capacity, but I will not care whether the capacity by which the kind is defined is one that explains how the kind came to be." And for good reason, because what is traditionally seen as the alternative conception of functionthe etiological, teleological, or selected-effects one (Millikan 1984; Neander 1991) - incorporates a historical dimension that is difficult (if not impossible) to accommodate with the presumed synchronicity of $\mathrm{R}_{\mathrm{F}}$. Millikan (1999) somewhat sensed this in her rejection of the Fodorian conception of 'Special Sciences,' which, according to her, should be replaced by that of 'Historical Sciences' as those disciplines dealing with 'historical natural kinds.' This paper by Millikan elicited a rather irate response from Richard Boyd, who wrote (Boyd 1999: 91): "Your liver is multiple (sic) realized: its exact physical realization varies from moment to moment, and human livers generally are to a greater extent multiply realized." Boyd finds this unproblematic, but as we will immediately see, the problem is not only a hepatic one, but may also be a cardiac one. The crucial point is that realization appears to have serious difficulties with history.

However, corkscrews have functions, mousetraps have functions, carburetors have functions, all artifacts, in fact, have functions. The whole account of $R_{F}$ undoubtedly rests on the analogy between organisms and artifacts and, as we have repeatedly observed already, most discussions of realization transit freely from the world of machines and manufactured objects to the biological world. Therefore, if Polger and Shapiro want their theory of realization to apply both to artificial and organic entities, they need teleological functions. This may explain why Polger and Shapiro have maintained a relatively equidistant stance with respect to function, yet teleological functions nonetheless need history, and $\mathrm{R}_{\mathrm{F}}$, by definition, is ahistorical. Granted that teleological-function talk in biology is a debated issue, but this does not mean that the problem of time (or history) is not a problem for a view on realization as applied to biological entities. We shall now, as promised, turn our attention to hearts.

\subsection{Of skins and heart}

Let us revisit a classic textbook case. The point of a functional analysis of the fourchambered heart of mammals and birds is to understand how such a system achieves the capacity of pumping blood through the blood vessels of the circulatory system as a result of the activities of its parts. Thus in order to proceed with such an analysis, activities must be ascribed to different parts of the heart that clarify the function/ purpose with which they contribute to the characteristic capacity assigned to the heart as a whole. For example, one thing which is crucial to the heart's performance is a restricted group of cardiomyocytes (maybe a $1 \%$ of all cardiomyocytes) with the inherent capacity to generate action potentials. This electrical activity is transmitted 
to the rest of the heart's tissues, paving the way for a spontaneous contractile behavior that will eventually be coordinated by a modified group of cardiomyocytes (the pacemaker), located in the wall of the right atrium of the heart (sinoatrial node). The pacemaker has conductive properties and it is connected to the neighboring contractive cells through junctions that enable it to control the depolarization and action potential of these other cells. The pacemaker's own weaker contractions allow the cardiomyocytes to contract in a coordinated fashion and thus the heart behaves as a unit.

For the time being, let us concentrate on the contribution of standard cardiomyocytes to the capacity generically assigned to the heart-i.e. pumping blood through the blood vessels of the circulatory system. According to the previous analysis, there certainly is a characteristic activity that may be identified as the function/purpose that standard cardiomyocytes contribute to the generic capacity of the heart, namely that of generating muscle contractions. We can, therefore, conclude that standard cardiomyocytes $(S C M)$ are the realization of a 'muscle contractor generator' $(M C G)$, for they have the function $\mathrm{F}_{\mathrm{mcg}}(x)$ in the specified sense. So far, so good. There is, however, one detail that leads us to regard this conclusion as unlikely.

The heart develops from mesodermal cells which initially form two independent endocardial tubes that eventually fuse together to form what will be the fourchambered heart. At the time heart contractions start-around day 22 in the case of the human embryo, the fusion of the endocardial tubes has hardly finished and there is no evidence of anything resembling a four-chambered heart. Such a structure only comes into sight with the formation of the septa, which usually occurs in the seventh week of human development (Gilbert 2014: 450ff). Muscle contraction-the designated activity/function/purpose of standard cardiomyocytes - therefore, largely predates (in developmental tempo) the formation of the heart and the performance of its generic capacity.

The whole realizationist edifice succumbs to this conclusion, at least for this particular case. Note that even if we maintain that 'muscle contraction' is the functional contribution of standard cardiomyocytes to the generic capacity of the heart, we cannot maintain that the relation of standard cardiomyocytes with such an activity is one of realization, for the activity (and the relation) predates the function. In other words, there is no 'synchronicity,' and the relation cannot, therefore, be one of realization. As an apparently straightforward escape hatch from this argument, Polger and Shapiro might answer that at $\mathrm{t}_{1}$-a temporal slice prior to the instantiation of the four-chambered heart, the system in which the cardiomyocytes are embedded is a different one, and that function attribution runs smoothly within that frame. Consequently, development could unproblematically be integrated into the paradigm, viewing it as serial episodes of functional change that run parallel to the transformation of systems along the temporal axis. For such a view, then, diachrony is a perspective that is reducible to the synchronic one-but not the other way around. We believe this view to be problematic, because if there is one perspective that is but an abstraction of the other in the life sciences, that is the synchronic one. Moreover, referring cardiomyocytes - or any other component part of whatever organic system-to different systems across time, merely multiplies the problems raised in this section regarding the realizationist thesis. We shall turn to this issue in 3.3. 


\subsection{The heart of the mind}

Consider now a different example, one that is quite unusual in philosophy of biology forums but, we believe, quite legitimate, at least since the publication of Eric Lenneberg's Biological Foundations of Language (Lenneberg 1967). In all likelihood, language provides some of the most distinctive psychological states in humans. That being the case, it may at first sight appear not to be the best source of examples for the ongoing discussion, as it is questionable whether nonhuman brains provide counterparts that can be used to defend their being multiply realized in different organisms, and, accordingly, realized at all. However, as we have previously claimed in this paper, the issues of 'realization' and 'multiple realization,' while obviously related, belong to different debates. Realization might exist even in a world where all psychological states are singly realized. Thus, language, even if purportedly an inadequate source of arguments in favor of multiple realization, is, in contrast, good ground on which to debate realization simpliciter, as we shall defend in the following paragraphs, regarding the flat-realizationist family in particular.

As already noted, the 'flat view' is centrally committed to the idea that realizing a certain psychological state is tantamount to having a function, obviously displayed by the brain or some subsystem therein. We argued before that only 'causal role' functions appear to be apt to fit this bill, as they are the ones that can answer the 'synchronicity' property that is considered to be definitional of $\mathrm{R}_{\mathrm{F}}$. Let us then remember what exactly these amount to. The characterization below is the one offered by Shapiro (2004):

The point of a functional analysis of a system is to understand how a system achieves some capacity by way of the activities of its parts. [...] Functional analysis proceeds by assigning functions to the parts of a system, where these functions are better associated with purposes or goals [...] (Shapiro 2004: 20)

According to this description, to defend the idea that a certain type of brain state realizes a distinctive type of psycho-linguistic state entails equating the latter with a certain function (capacity, purpose, goal) distinctly carried out by the former, within the context of the language system as a whole, thus providing the frame within which such a functional contribution makes sense. However, as argued above regarding this specific kind of flat realization, the type of activities that ultimately provide such functional contributions commonly predate the system which benefits from them, obviously contradicting Shapiro's and other related functional projects. Indeed, language provides some illustrative examples of such developmental mismatches between the onset of certain language-related activities and the emergence of a steady language system in the mind of children.

Linguists customarily partition language into two basic components, which jointly-i.e. through some kind of interface-comprise a basic, universal blueprint attributable to any language-particular system, namely a 'lexicon' (i.e. a repository of meaningful minimal units; henceforth, $\mathbf{L}$ ) and a 'computational system' (i.e. a recursive procedure apt to generate an unbounded array of structured expressions, ultimately based on the lexical repertory; henceforth, CS). This minimal architectural specification is considered to be definitional of language, 
in that it appears not to make sense to speak of $\mathbf{L}$ in the absence of $\mathbf{C S}-$ or the other way around, or of language in the absence of any of these components. The idea is aptly captured by the following quote from Chomsky (1995), who uses the 'virtual conceptual necessity' expression to refer to the definitional character of the corresponding architectural pattern:

A [...] standard assumption is that a language consists of two components: a lexicon and a computational system. The lexicon specifies the items that enter into the computational system, with their idiosyncratic properties. The computational system uses these elements to generate derivations and SDs [structural descriptions]. The derivation of a particular linguistic expression, then, involves a choice of items from the lexicon and a computation that constructs the pair of interface representations. So far we are within the domain of virtual conceptual necessity, at least if the general outlook is adopted. (Chomsky 1995: 168-169)

Note that all this appears to be good news for a realizationist interpretation of the linguistic enterprise. A functional analysis of the language system is easily attainable and would consist of understanding how language achieves its human-typical capacities by way of the activities of its parts-i.e. lexical selection, Merge (the name routinely given to the basic structure-building operation of $\mathbf{C S}$ ), etc. Therefore, under the umbrella of the steady language system, one could proceed to assign functions to $\mathbf{L}$ and $\mathbf{C S}$ in terms of purposes or goals, thus concluding that distinctive brain states realize the corresponding functional states. So far, so good. The problem is that the parts of the systems are not as tightly interwoven as the realizationist thesis requires.

For example, Bates and coworkers have documented that the best predictor of mean length of utterance (MLU) at approximately the age of $\pm 2 ; 6$ (2 years; 6 months), coincidental with the onset of an incipiently productive syntax, is vocabulary size at $\pm 1 ; 8$, where no syntax whatsoever exists (Bates et al. 1988: 142ff; see also Marchman and Bates 1994: 364; Marchman and Thal 2005; McGregor et al. 2005). Let us stress a couple of consequences of this empirical finding which are important for our own interests:

1. $\mathbf{L}$ and $\mathbf{C S}$ are dissociable entities - and not merely as an exercise of conceptual abstraction. Prominently, $\mathbf{L}$ predates the full-fledged dual system. In all this, $\mathbf{L}$ is, to the language system as a whole, very much like the standard cardiomyocytes to the circulatory system. Consequently, irrespectively of what name one decides to assign to the contribution of $\mathbf{L}$ to the language capacity, it appears to be clear that it does not qualify as a causal-role function, contrarily to what is required for the completion of the flat realizationist thesis.

2. Characterizing the function of $\mathbf{L}$, for example, as that of providing the minimal constructive materials to $\mathbf{C S}$ once the language system is operative, falls short of offering a rigorous image of L's capacities: one of the central ones, and one that obviously predates the steady language system, is the developmental role of inciting and scaffolding the growth of CS, as Bates and coworkers' finding 
clearly suggests. Indeed, these kinds of developmental roles are pervasive in nature (Minelli 2003; Oppenheim 1981, 1984). To cite just one case, the cuticle of some organisms first controls growth and body size via mitosis in the epidermis, and only serves as a mechanical or protective device afterwards (Minelli 2003: 12ff). Clearly, function ascription is a more complex enterprise than $R_{F}$ appears to presuppose. Functional profiles vary in developmental time and, in the end, appear to be but a fuzzy, entangled net of actions and reactions, ultimately given by the primary properties of the active units themselves, yet modulated by the varying environmental circumstances - both in an organism-internal and external sense (Anderson 2010; Balari and Lorenzo 2018; Bergeron 2007; Bock and von Wahlert 1965; Love 2007; Mahner and Bunge 2001; Wouters 2003).

\subsection{The dismissal of explanation}

Polger (2010) introduced a distinction between 'descriptive' and 'explanatory' approaches to realization and argued that only $\mathrm{R}_{\mathrm{F}}$ is explanatory because it can play an informative role in scientific explanations. But, what informative role can $\mathrm{R}_{\mathrm{F}}$ play in the case of the heart or in the case of language, where the explanation is developmental? Take again the specific case of standard cardiomyocytes (SCM): Once we know that they acquire their capacity for generating muscle contractions at a developmental stage at which the heart does not even exist, it becomes clear that it is into development that we must delve in order to understand how SCM fulfill such a role when later developmentally incorporated into the heart's architecture. Nothing is gained by simply calling them 'muscle contractor generators,' which is but a labelling exercise-ultimately, simply a speech act. If, as claimed by Polger and Shapiro (2016: 30), explanatory approaches are those that "can help to explain the sorts of manipulations and changes [something] can survive," it is thus clear that in the case of organic entities, such as SCM, the heart as a whole, $\mathbf{L}$, the language system, etc., where one must look is in the continuum growth-assemblage-steady functioning, and that the best cover term for such a continuum is but 'development.'

However, as pointed out by an anonymous reviewer, what if we take the whole organism and its self-maintenance as the target of functional explanation? We believe that, if we were to do so, the whole functional/realizationist edifice would definitely collapse, for several reasons. Note that in such a scenario, every single activity of every single organic entity would be exercising an overarching developmental role, perhaps open to an array of developmental specializations. The position clearly leads to a sort of pandevelopmentalism, which is problematic, to begin with, because development is not a function that organisms realize. It is not even a function. When one adopts the temporal perspective that the idea suggestsi.e. the one resulting from "synchronizing" an entire life-cycle, development is exactly what one perceives, namely, the ever-changing reconfiguration of an organism. However, functions are not something that is observed, but something that is ascribed, two very different things. Development is what being an organism ultimately amounts to; but organisms do not develop 'for' anything. Development simply happens. Development has consequences, of course, but, from the point of view 
of the organism, they are completely unexpected (Gottlieb 2007). Development and realization are completely uncongenial categories, and developmental explanations have little (if anything) to do with functional explanations. A formula like the one for $\mathrm{R}_{\mathrm{F}}$ above clearly does not apply to development. Note also that the life-cycle of an organism overlaps those of its progenitors and descendants, compounding indefinitely extended chains of developmental cycles (Griesemer 2000; Minelli 2003, 2011). Development and evolution certainly overlap and, from a certain perspective, they are but the same process. It is thus also tempting to "synchronize" the resulting extended life-cycle, with the result that the functionalist perspective would then suggest "evolution" as the relevant term of functional explanations. The resulting panevolutionism would repeat ad infinitum the previous shortcomings.

The same reviewer raises the relevant question as to whether the challenge that we pose to the realizationist/functionalist perspective also runs against the decomposability principle, which we are implicitly assuming. The answer is "no," but with the following important qualification. As brilliantly expounded in the opening pages of Waddington (1957), decomposability does not mean the same when applied to artifacts as when applied to organisms. In the case of the former, decomposition precedes observation; in the latter, it is a result of observation and cannot be taken for granted. Besides, one cannot ascribe a particular decompositional pattern to an organism without having independently justifiable grounds (a "point of view," in Waddington's words; see also Kauffman 1970 and our considerations below in connection with the dimensioned view). The best qualified grounds to-date for justifying the mosaic-like or modular composition of organisms are, once more, of a developmental nature: namely, what qualifies as a bona fide organismal part is that which behaves as a developmental unit-ultimately referring to a self-contained and semi-autonomous network of original molecular products, responding to specific signaling pathways and obeying typical patterns of interactions (von Dassow and Munro 1999; Wagner 1989a, b, 2007, 2014). Again, organic decomposability is not a synchronic quality, but a diachronic one.

Development (and evolution) are a problem for realization theories, but development and evolution (and metabolism; Waddington 1957: 6, 1968: 526) are at the core of any biological theory. Realization, as far as the flat view is concerned, is not capable of capturing even the basic facts of developmental or evolutionary analyses (not to mention evolutionary developmental ones), since these critically involve considerations where processes, time, and history are central. What is the use of a theory of realization that is incapable of taking these into account? Close to nil. Perhaps the dimensioned view fares better...

\section{The dimensioned view}

The story of the dimensioned view on realization starts with a diamond called $s *$. Gillett (2002) tells us that $s^{*}$ is extremely hard, as is to be expected from any diamond, but that this property can only be accounted for by appealing to the particular relations of alignment and bonding of the carbon atoms that are the constituents of $s^{*}$. Thus, Gillett concludes, the hardness of $s^{*}$ "is realized by the relations/properties 
of the carbon atoms" (Gillett 2002: 319; emphasis in the original). As can easily be appreciated, here we have a property of a whole, the hardness of $s^{*}$, which is not (cannot be) a property possessed by any of its parts (the atoms) but which is however a consequence of the fact that the parts are organized in a specific way. Therefore, so the argument goes, hardness, a higher-level property, is collectively realized by the properties of the lower-level entities. Gillett later streamlined his account in two new papers (Gillett 2003, 2007) and eventually found an ally in Kenneth Aizawa, who had himself constructed an argument against Bickle's (2003) reductive account of memory consolidation, challenging the proposal on the grounds of the multiple realization of the phenomenon, given the differences in protein structure observed in different animals in which it had been observed (Aizawa 2007). A number of joint publications ensued (e.g. Aizawa and Gillett 2009, 2011), and the canonical definition of dimensioned realization $\left(\mathrm{R}_{\mathrm{D}}\right)$ to date is the one to be found in Aizawa and Gillett (2009: 186; also Aizawa and Gillett 2011: 206).

According to this definition, a property (or a set thereof, call them $F_{1}-F_{n}$ ) may realize a single property $G$ whenever the realized property has powers that somehow inherits from the set of realizer properties $F_{1}-F_{n}$. Technically, $R_{D}$ may be flat (but also one-to-many, unlike its cousin $\mathrm{R}_{\mathrm{F}}$, which is always one-to-one), since the collection of properties $\mathrm{F}_{1}-\mathrm{F}_{\mathrm{n}}$ may be of properties of the individual $s$ or of the constituents of $s$. The latter is, basically, the case of the diamond called $s^{*}$.

Thus, for example, and going back to the case of memory consolidation (Bickle 2003; Aizawa 2007), since what biochemists call protein kinase A (PKA) in different animals corresponds to non-identical amino acid sequences, then memory consolidation is multiply realized (Aizawa and Gillett 2009: 198-199); or, since in human color vision the chemical photoreceptors show polymorphisms that contribute to slightly different absorption spectra, then human color vision is multiply realized (Aizawa and Gillett 2011: §10.3).

\subsection{Levels strike back}

Gillett (2007) makes the explicit claim that $R_{D}$ is the perfect ontic complement to the epistemology of explanation as developed under the label of 'Mechanistic Explanation,' referring here to both Fodor (1968) and Cummins (1983) and to the so-called new-mechanists (Machamer et al. 2000). While this putative connection has not been received with great enthusiasm by some new mechanists (e.g. Craver 2007: Chs. 5-6, also 2015; Glennan 2017: 48-56), it is undisputable that there exists an intellectual link between dimensioned realization and mechanistic philosophy in the work on the analysis of complexity, reduction, and emergence by William Wimsatt (e.g. Wimsatt 2007). Aizawa and Gillett often refer to Wimsatt as a precursor (especially Aizawa and Gillett 2009) in the use of the locution 'multiple realizability' in contexts that closely remind the relation of dimensioned realization. As far 
as we can tell, Wimsatt has done this twice: once in Wimsatt $(1994)^{2}$ and once in Wimsatt (2002).

Let us consider the case of the first of these papers, which is perhaps the most relevant for the case in point. Firstly, we deem it crucial to underscore that Wimsatt's goal is mostly descriptive here and that he somehow extends the taxonomy of levels he established in Wimsatt (1976). Another relevant point is that Wimsatt aligns himself with a current of thought for which the fundamental structure of the world is merely a rich network of causal processes, perhaps understood as informationtransmission processes (in the physical and mathematical sense of the term)-Wimsatt 2007: 200, and Salmon 1984; Smolin 2001; Ross and Spurrett 2004; Ladyman et al. 2007, for several formulations of the idea. Therefore, Wimsatt's conception is inherently dynamic, which immediately suggests that there is likely to be some clash between it and the essentially static view of realization defended by Aizawa and Gillett. It is from this conception that stems Wimsatt's definition of level of organization: put succinctly, that levels are regularities that emerge from 'concentrations' or 'condensations' of regularities in certain areas of the world; in other words, levels are something not too different from what Dennett (1991) would call 'real patterns' (Ross 2000, for discussion).

Wimsatt is a realist regarding levels of organization, seeing them as real patterns that reflect the hierarchical organization of the world into part-whole relations. He nonetheless recognizes that such part-whole structure should not be overestimated in the sense that it is not always possible to apply what he calls the 'engineering paradigm', especially in the case of biological systems; indeed, Wimsatt sees this as a very good heuristics, but one with obvious limitations and therefore one that must not be taken at face value (e.g. Wimsatt 2007: 202, 1976). It is in this context that Wimsatt observes that there is nothing exceptional about the "multiple realizability, or the dynamical autonomy of upper-level phenomena," since these are intrinsic to the emergent (in Wimsatt's sense; see Wimsatt 1976, 2007: ch. 12) nature of such phenomena (Wimsatt 2007: 217). It should, however, be noted that, for Wimsatt, this has mere observational or descriptive value, because what is relevant is the regularity or the robustness (Wimsatt 1981) of the phenomena and, in any case, it is something that is never an obstacle to deriving the appropriate mechanistic explanations of the said phenomena (Wimsatt 2007: 276). It should be clear by now how small a role multiple realizability plays in Wimsatt's scheme for the analysis of reduction, explanation, and emergence, certainly nothing comparable to its centrality in Aizawa and Gillett's model.

At this point, Aizawa and Gillett might want to retort that what Wimsatt's framework is lacking is an explanation of how the different levels are actually made up and that $R_{D}$ is precisely the kind of metaphysically necessary (and sufficient?) relation that is needed. This is in fact the direction in which both Aizawa and Gillett are moving, since their most recent projects focus on the attempt at making ontic sense

\footnotetext{
2 All page references to this paper are to its reprint as Chapter 10 of Wimsatt (2007), where it appears together with other articles dealing with similar topics and a unifying introductory text also including some sporadic reference to multiple realizability.
} 
of the myriad of locutions scientists use to refer to 'vertical compositional relations' and, of course, on demonstrating that the answer is in $R_{D}$ (Aizawa and Gillett 2016; Aizawa 2016; Gillett 2016). In this, we tend to align with Polger (2010) in stating that $\mathrm{R}_{\mathrm{D}}$ does not really go beyond telling us when and that (multiple) realization occurs, but falls short when it comes to explaining why or how some asymmetric dependence exists between entities at different levels. To be sure, Aizawa and Gillett do not go very much beyond the point Wimsatt left us at when he asserted that multiple realizability is to be expected: of course, there's multiple realization galore! Perhaps Wimsatt's choice of words was unfortunate (we honestly believe it was) and the issue turns out to be simply a terminological one (a solution Polger abhors), but it is also true that Wimsatt has something else to add to this. For him, the key constitutional notion is not 'realization' but 'organization' (and the associated notion of 'robustness;' see below our concluding section), which he defines in the negative as the extent to which a system approximates non-aggregativity, that is the state in which a system's properties do not depend upon the properties of its parts "in a very strongly atomistic manner, under all physically possible decompositions" (Wimsatt 2007: 277, 280). Perhaps this is not a very accurate definition, but it is the one that best agrees with scientific practice (von Bertalanffy 1952; Waddington 1957; Kauffman 1970, 1993; Moreno and Mossio 2015, for a recent and comprehensive study), a commitment (with scientific practice) that Aizawa and Gillett have always made explicit in their papers.

\subsection{Mental causal thickets: an illustration}

The shortcomings of $\mathrm{R}_{\mathrm{D}}$ thus far commented are dramatically exemplified by the following case, taken again from the domain of language. In what follows, we shall focus on a property routinely ascribed to language, which has to do with the highest level of structural complexity that linguistic expressions may attain. In our illustration such a property is intended to be understood as comparable to the extreme hardness of $s^{*}$. Here, we shall conceive such a level (unproblematically) as a feature of CS. CS is commonly decomposed into two main components, namely, a sequencing procedure - e.g. the pairwise recursive operation Merge of Chomsky (1995) and subsequent works, and an operative memory device that keeps the ongoing computed expression active for further manipulations. In terms of structural or formal complexity, language is routinely said to belong to the family of (mildly) contextsensitive languages (Joshi 1985)_equivalent, in mechanism terms, to an enhanced push-down automaton (Balari and Lorenzo 2013). Such a characterization entails that linguistic expressions may not only contain local relations (1) - like regular languages - and long-distance embedded ones (2) - like context-free languages, but also relatively complex patterns of crossing relations (3), where subindices identify words standing in some grammatical relation like agreement:

1. $\mathrm{John}_{\mathrm{i}} \operatorname{sing}_{\mathrm{i}}$

2. The guy $_{\mathrm{i}}$ that some people $\mathrm{j}_{\mathrm{j}}$ wrongly call $\mathrm{J}_{\mathrm{j}}$ John sings $\mathrm{s}_{\mathrm{i}}$

3. The guy $_{\mathrm{i}}$ that his $\mathrm{s}_{\mathrm{i}}$ mother $_{\mathrm{j}}$ wrongly calls $_{\mathrm{j}}$ John $\operatorname{sings}_{\mathrm{i}}$ to her ${ }_{\mathrm{j}}$ every morning 
In mechanism terms, such increasing levels of structural complexity are a function of the increasing memory capacity accessible to CS (Balari and Lorenzo 2013). Based on this observation, one may claim that certain states of the human brain realize an enhanced push-down automaton, which, according to the dimensioned version of realization, would be a property (henceforth, PDA+) directly derived, and with powers inherited from, certain brain components obeying a distinctive pattern of organization-themselves lacking such a property. However, the issue is less simplistic than that — but, fortunately, maybe also less mysterious.

First of all, the PDA+ property is a dynamic one. We conventionally say that a system of computation is or is not associated to a PDA+, but, as a matter of fact, what one really wants to express is that the system is associated to a memory device which, on occasion, displays the PDA + property in the sense above. Furthermore, examples (1) to (3) above may be assumed to be processed by one and the same human language system - say, yours-yet without manifesting the PDA+ property in (1) and (2), the former being a manifestation of the FSA property (for 'finite state automaton'), and the latter of the PDA property (i.e. non-enhanced PDA). In other words, a brain system does not realize the PDA+ property right away. More is needed: crucially, such a brain system must interact with the right kind of input-i.e. expressions like (3).

Let us emphasize the dynamic character of the property of interest, capturing it more closely from a developmental perspective. Expressions displaying the kinds of convoluted relations illustrated in (3) above can reasonably be considered a necessary-yet not sufficient - ingredient for a system of computation to attain the PDA+ property of interest. In other words, the system must be attuned to the kinds of input that force it to display the property. This claim is dramatically illustrated by the following situation, which is also illustrative of a further issue of interest for our case: Expressions in natural language may contain formal specifications of the relations typically held at a long distance and potentially resulting in crossing patterns. ${ }^{3}$ Actually, this is the case of the items that appear within brackets in (3'):

(3') The guy $_{\mathrm{i}}$ that $[\text { his }]_{\mathrm{i}}$ mother $_{\mathrm{j}}$ wrongly call $[\mathrm{s}]_{\mathrm{j}}$ John $\operatorname{sing}[\mathrm{s}]_{\mathrm{i}}$ to $[\text { her }]_{\mathrm{j}}$ every morning

Note that the use of his-instead of her-indicates that the pronoun relates to the distant masculine item guy - the same in the case of her, in reference to the feminine mother; and, similarly, the use of the suffix $-s$ in calls and sings indicates that the respective verbs relate to the distant third person items the guy and his mother. One

\footnotetext{
3 The following clarification is in order. These kinds of formal markers are not systematically used to make explicit long-distance dependencies. In some prominent instances-as e.g. the connection between fronted interrogative pronouns and their base position, the second element is not even pronounced: e.g. What ${ }_{\mathrm{i}}$ did you say that Peter saw $\Delta_{\mathrm{i}}$ ? In most cases, long-distance connections are implicit-i.e. not explicitly marked: e.g. I said $\mathrm{i}_{\mathrm{i}}$ that Peter saw an unexplained flying object jokingly ${ }_{\mathrm{i}}$. Among other arguments, Balari and Lorenzo (2018) base on such an unsystematic character the idea that markers primarily serve to scaffold the capacity for establishing connections — see below in main text-rather than to express them. Lorenzo (2018) points out some relevant parallels in the domain of locomotion.
} 
intriguing thing about such a formal makeup is that it does not contribute to the content of the expression at all. This fact has led to this kind of linguistic material being referred to as 'non-interpretable' (Chomsky 1995). The issue of what its role may possibly be in a language system is an obscure and open one (Barlow and Ferguson 1988). However, a reasonable developmental explanation is provided in Balari and Lorenzo (2018) and Lorenzo (2018), based on some clinical findings made by Harald Clahsen and coworkers.

In a collection of papers (Clahsen 1986; Clahsen and Hansen 1997; Clahsen et al. 1997), Clahsen's team observed that children with a diagnosis of a developmental impairment specific to language had problems both in correctly using the kinds of units referred to above as containing non-interpretable material, and in establishing long-distance dependencies between units within the same linguistic expression. Moreover, they also observed that there existed a kind of causal relation between these phenomena, which specifically pointed from the correct use of non-interpretable material to the well-formedness of expressions in terms of expected long-distant connections. In short, when children were subjected to rehabilitation specifically focused on the former, their performance in the latter also spontaneously improved, but not the other way around. Based on this datum, Balari and Lorenzo (2018) suggest that units containing non-interpretable material have a developmental role within the system of computation, namely that of scaffolding the achievement of the capacity for processing with the powers associated to the PDA+ property.

Balari and Lorenzo's approach provides a further insight relevant to the issue. Crucially, they note that the kinds of units of concern, mostly agreement and case systems, vary enormously from language to language (Blake 2001; Corbett 2009), and that they obviously pertain to the learned component of particular languagesi.e. to the component traditionally inherited from the historical speaking community of the learner. This entails that units with the kind of scaffolding role specified in the previous paragraph are ultimately of an organism-external provenance, yet they end up being part and parcel of the system of computation capable of manifesting the PDA+ property. From this, Balari and Lorenzo (2018) conclude that language is a case of developmental hybridization (Chiu and Gilbert 2015; Giorgi and Bruni 2015; Griesemer 2014a, b), partially made from external and internal contributors, but in the end transcending one and the other characterization.

Against this background, the following far-from-trivial conclusion follows. The items associated to non-interpretable material are active participants in the overall computational capacity of the brain, both in development and actual processing, as scaffolds and markers of the PDA+ property, without being — or exclusively beingpart of the brain 'lower-level' properties that make such a property possible. Their role in relation to the property of concern belongs to the causal domain. Yet, as Balari and Lorenzo (2018) stress, they are not causal in a determinate or absolute way. Rather, they belong to a sort of 'causal thicket,' in the sense of Wimsatt (2007), which comprises an entangled net of external and internal agents that makes possible the attainment of the PDA+ property by $\mathbf{C S}$, despite the probabilistic character of the process (Gottlieb 2007); in other words, they contribute to making the developmental and computational process 'robust,' by being one among many agents that overlap and interact with each other, in a way that dispenses with the need for them 
to be uniformly present or active at every developmental scenario (Bateson and Gluckman 2011). As Balari and Lorenzo (2018) remind us, case and agreement systems may manifest together or independently, be more or less complex in the number of entailed units and features, or even be practically absent in certain languageparticular systems - in which some other agents purportedly take their role.

To conclude, such a distinctive property of the human brain as the one that we have been referring to here as the PDA+ property cannot be simplistically said to be realized by the properties of certain distinctively organized brain states. Rather, the property must be said to be distributed among many different agents, of different proveniences, which may manifest differently from one occasion to another, while all nevertheless belonging to the same system of development responsible for efficiently installing and putting to work a powerful $\mathbf{C S}$ in the human mind.

\subsection{The dismissal of scientific practice}

Just as we concluded regarding Polger and Shapiro's flat view, the dimensioned view of realization does not appear to attain bona fide explanatory force either. Perhaps the clearest demonstration of how Aizawa and Gillett's approach is merely descriptive is the extent to which, declarations of intentions notwithstanding, they actually ignore scientific practice.

Let us go back to proteins (Aizawa 2007; Aizawa and Gillett 2009, 2011). Recall, for example, the case of PKA, a key element in the process of memory consolidation discussed by Bickle (2003). As reported by Aizawa and Gillett (2009: 198; also Aizawa 2007), PKA has different amino acid sequences in different organisms, which preserve nonetheless the required function to participate in the process in question. Thus, Aizawa and Gillett (2009: 199) conclude, "we actually have a paradigm case of multiple realization." Indeed, the authors foresee that the case generalizes because "[e]ven homologous proteins will differ to a greater or lesser degree in their amino acid sequences, so that they will differ to a greater or lesser degree in their physico-chemical properties" (Aizawa and Gillett 2009: 200). These words are illustrative, because they suggest that Aizawa and Gillett are here disregarding what counts as the same or different in the sciences, in molecular biology in this case. They appear not to be at all impressed by the fact that biologists and biochemists consider these proteins homologous and have developed their methods to determine homologies at this (and other) levels (Koonin 2005 for an overview). This line of attack is not new (see Bechtel and Mundale 1999; Couch 2004, 2009; Balari and Lorenzo 2015), but given its importance it may be relevant to buttress it.

Consider first the theory of evolutionary innovation developed by Wagner (2011). The question of 'innovation' in biology is a vexed one (Brigandt and Love 2010, 2012), but clearly one intimately connected with the problem of telling what is different from what is not, given a complex landscape of immense degrees of variation. A. Wagner's approach is fairly abstract as it is directly inspired by the concept of a protein space originally developed by John Maynard-Smith (Maynard-Smith 1970), and in analogy with which A. Wagner defines the concept of a protein genotype space. Such a space is formed by all possible amino acid strings for a specific 
number $S$ of amino acids. Therefore, protein genotype space contains $20^{\mathrm{S}}$ elements, where $S$ is an integer encoding the total number of amino acids in the sequence. As A. Wagner observes, this space may be conceived of as a network of connected genotypes such that each sequence is connected to all other sequences differing in only one amino acid. Given this, there is always a path going from some randomly chosen sequence to another, and the distance separating them is simply the number of mutations in which they differ. More important, though, is the phenotype space associated with the protein genotype space. A. Wagner defines the phenotype of a protein as either its fold or its biochemical activity and, accordingly, one can identify, within the genotype space, subsets of connected genotypes that are associated with exactly the same phenotype; that is, the genotype-phenotype relation is many-to-one: there are many more possible genotypes than there are possible phenotypes. Note, by the way, that homology in the sense of common descent (Koonin 2005) is not involved here, since for A. Wagner what is relevant is identity of function and/or identity of structure. Therefore, we could certainly assert that each of the phenotypes that conform protein phenotype space are multiply realized, since each would have more than one underlying genotype. But such an assertion would be simply restating the fact that phenotype space is smaller than genotype space, which is a given in A. Wagner's model. What would be of interest here would be, for example, whether there is a fixed amount of change at the genotype level that is necessary in order to go from one phenotype to another, or in other words if there is a fixed distance that a specific genotype must traverse in a random walk within genotype space in order to hit a new phenotype. Nothing in this explanation would hinge on the presence/ absence of 'realization' in one's conceptual (descriptive, metaphysical) toolbox. For the sake of clarity, allow us stress the point of all this. It is one thing to say of a collection of organic entities, at whatever level of analysis, that they are differently the same-i.e. homologues - and another, very different thing to see them as different realizations of the same. It is the use of the word 'realizations' in particular that we contend that is explanatorily idle. Using the idea of 'variation' to refer to that of 'homology' is tautological, associating the idea of 'realizer' to that of 'homologue' is vacuous. In other words, 'homology' entails 'variation', while realization does not add anything to the 'homology/variation' conceptual relationship.

Let us take now a more complex example, as is G. Wagner's theory of homology and character identity (Wagner 2007, 2014). This theory culminates G. Wagner's more than 25-year quest for a biological (i.e. developmental) concept of homology (Wagner 1989a, b), which grounds assertions of identity of characters, understood as body parts, on the basis of shared developmental resources. In a nutshell, two characters are identical if their identity is based on the continuity of the underlying identity networks (General Homology; Wagner 2014: 418), where an identity network (or Character Identity Network; ChIN) is defined as a module of "genes and gene regulatory networks that interpret positional information signals and activate specific position-specific developmental programs" (Wagner 2014: 97). This definition nonetheless allows ample room for variation, since two identical characters may be present in different states in different animals. A case in point is insect wings. If we take a butterfly as a point of reference, we see that these insects have a pair of wings associated with the second thoracic segment (forewings) and another pair of 
wings associated with the third thoracic segment (hindwings). Take now a fly or a mosquito, whose wings correspond to the forewings of the butterfly, while in place of a set of hindwings flies and mosquitoes have a pair of flight-stabilizing structures known as halteres. Finally, beetles, ladybugs, and other coleoptera possess a pair of hindwings and in the place of forewings have elytra, a protective shell-like structure that is raised when the animal extends its wings to fly. Despite these structural (and functional) differences, the body parts we observe associated with the second thoracic segment in different insects have the same character identity, i.e. they are homologous; similarly with those parts associated with the third thoracic segment. The point is that homologous characters may present different character states while maintaining their identity. Other examples of characters with the same identity would be, for example, the paired fins in fish and the paired limbs in tetrapods, or epidermal scales and feathers. The different states of these characters are the responsibility of a downstream module of 'realizer genes' controlled by the ChIN genes.

We have brought this example to the fore because we believe it to be pertinent to the discussion for several reasons. One is that, as a quick inspection of the definition of General Homology immediately reveals, G. Wagner's theory of homologs is a theory of biological kinds. Indeed, the author has repeatedly made explicit his metaphysical commitments - in several publications, but see in particular Wagner (2014: ch. 7) — as to the reality of homologs (see Brown 2015; Haig 2015; Love 2015; Wagner 2015). The specific metaphysical framework G. Wagner invokes to ground his claims is the Homeostatic Property Cluster (HPC) view of natural kinds originally devised by Boyd (1991, 1999) as amended in Wilson et al. (2007), Assis and Brigandt (2009), and Brigandt (2009) to incorporate the necessary historical dimension required in the particular case of homologs (but also species and other taxa, for example); see Brigandt (2017) for an overview. Thus, within this framework, we are able to assign the property, say, 'appendage of the second thoracic segment of $X^{\prime 4}$ to the forewings of a butterfly or of a mosquito, to the elytra of a ladybug or to the halteres of a strepsipteran, by virtue of the fact that all these characters are based on the continuity of the very same ChIN. Similarly, and this is the second, related point we wanted to raise here, we can assert the relation of Special Homology (Wagner 2014: 417) that exists between, say, the arm of a human and the pectoral fin of a sea bass, on the basis of the fact that both are individualized body parts in both species and correspond to the same part in the most recent common ancestor of humans and sea basses, or, in property parlance, that both the arm and the fin share the property 'anterior appendage of a vertebrate' (or 'arm' or 'fin;' see footnote 4). Note the difference between general homology and special homology: the former defines kinds of body parts, whereas the second identifies as homologous pairs of instances of body parts in different animals.

\footnotetext{
${ }^{4}$ Not that researchers in this field are worried about naming conventions, something that was already pretty clear at least as far back as 1848 when Richard Owen proclaimed that it was legitimate to apply the word 'vomer' to the same (homologous) bone in humans, crocodiles, and whales, even though it doesn't look like a ploughshare in all cases (Owen 1848: 2-3). So, instead of the convoluted locution we used in the text, we might as well have used the shorter term 'insect wing', for example.
} 
Now, is there any sense in which we can say that the elytra of a ladybug realizes (dimensioned sense) the property 'insect wing' or that the anterior fin of a whale and the anterior limbs of a horse both realize instances of the same property 'vertebrate arm'? In our opinion, the answer can only be an emphatic 'no.' The reason is that there are no parts $F_{1}-F_{n}$ of the elytra or of the whale fin whose powers together contribute to the powers that are individuative of the powers of the property 'insect wing' or 'vertebrate arm,' because the powers that are individuative of 'insect wing' and 'vertebrate arm' derive from the respective ChINs, which in no sense can be seen as a part of the organs in question. Crucially, note that the relation between the ChIN and the body part is causal (developmental and evolutionary) and $\mathrm{R}_{\mathrm{D}}$, as defined by Aizawa and Gillett, is explicitly characterized as a non-causal constitutive relation. To repeat our previous point regarding homology at the lower molecular level: The advantage of homology-based identity over the realization-based alternative is that the former belongs to a powerful explanatory apparatus based on verifiable causal effects, while the latter is an obscure metaphysical notion of no clear explanatory use. Every single explanatory virtue that one may be tempted to associate to realization-e.g. in explaining developmental drift, as suggested by a reviewer - can also be assigned to homology, but not the other way around. The problem, we hasten to clarify, is not endemic of constitutive non-causal categories at large, but specific to conceptual instantiations thereof, like $\mathrm{R}_{\mathrm{D}}$, with such a low explanatory profile.

\section{Conclusion: what all this points to}

If our criticisms in the sections above are on the right track, it then appears to be clear that the idea of 'realization,' at least in its two most popular incarnations reviewed in this paper, is far from attaining the explanatory relevance (Brigandt 2013 , 2015) necessary to account for the functional/dispositional properties that we have been reviewing. The current paradigm in biology is one that champions a more autonomous view of organic systems, easily assimilable into the theoretical trend known as ecological-evolutionary-developmental biology (Gilbert 2001; Gilbert and Epel 2015; Sultan 2007, 2015, 2017), whose renewed interest in organisms and processes runs counter to the subsumption of organisms to machines (Nicholson $2013,2014,2018$ ), a metaphor that is deeply entrenched in the realizationist frameworks reviewed here. This trend, moreover, smoothly meshes with the kind of diachronic biology advocated by the likes of Conrad Hal Waddington and others (Waddingotn 1969; Gilbert 2000), which was somewhat marginalized during the heyday of the New Synthesis (Peterson 2011; Nicholson and Gawne 2015, for a historical overview).

A concomitant consequence of the emergence of eco-evo-devo has been to extend the areas of interest which biology encompasses to variability (rather than just variation), evolvability (rather than just adaptation), and a whole collection of phenomena like modularity, robustness, and developmental constraint or developmental bias (Austin and Nuño de la Rosa 2018 for discussion and references), which require the adoption of a much more dynamic perspective than traditional realization 
frameworks are able to capture (Shoemaker 2007; Wilson and Craver 2007). Indeed, this does not necessarily mean that the traditional ontology of the life sciences must be replaced by the kind of full-fledged processual ontology advocated by Waddington and many others (e.g. Jaeger and Monk 2015; Dupré and Nicholson 2018, for two contemporary examples of this), but perhaps simply that it needs to be refurbished in order to grant processes the prominence they deserve (Pradeu 2018). Be that as it may, as we have tried to show in this paper, it stands to reason that 'realization' and 'multiple realization' have a central role to play beyond the trivial descriptive one of corroborating the obvious, that, for example, developmental systems are robust because they are capable of delivering the same results by different means (Wimsatt 2007: 196). In this context, what requires explanation is robustness itself and "to account for robustness is to account for multiple realizability" (Austin 2016: 656; emphasis in the original). Thus, and to briefly respond to an objection raised by an anonymous reviewer, we believe that it remains to be shown that 'realization' and 'multiple realization' have managed to go beyond their mere descriptive function, including in those cases in which those terms are used in connection with the phenomena of concern to eco-evo-devo, as, for example, in Austin (2016) or in Love (2018). Neither Austin nor Love provide any indication of what they mean by 'realization', whether it is $\mathrm{R}_{\mathrm{F}}, \mathrm{R}_{\mathrm{D}}$ or something entirely different, and until this is clarified, we can only reaffirm our suspicion that, as the key concepts of eco-evodevo find better and better explanations, 'realization' and 'multiple realization' will eventually be explained away.

Acknowledgements This paper has benefitted from a grant of the Spanish Government (FEDER/Ministerio de Ciencia, Innovación y Universidades - Agencia Estatal de Investigación) (Ref. FFI2017-87699-P) (SB and GL), and a grant of the Generalitat de Catalunya (SGR-2017-2019) to the Centre de Linguística Teòrica (Universitat Autònoma de Barcelona) (SB). We wish to thank two anonymous reviewers for comments and suggestions to a previous version of this paper. All remaining errors are our own.

Open Access This article is distributed under the terms of the Creative Commons Attribution 4.0 International License (http://creativecommons.org/licenses/by/4.0/), which permits unrestricted use, distribution, and reproduction in any medium, provided you give appropriate credit to the original author(s) and the source, provide a link to the Creative Commons license, and indicate if changes were made.

\section{References}

Aho, A. V., Hopcroft, J. E., \& Ullman, J. D. (1983). Data structures and algorithms. Boston, MA: Addison-Wesley.

Aizawa, K. (2007). The biochemistry of memory consolidation: A model system for the philosophy of mind. Synthese, 155, 65-98.

Aizawa, Kenneth. (2016). Compositional explanation: Dimensioned realization, new mechanism, and ground. In K. Aizawa \& C. Gillett (Eds.), Scientific composition and metaphysical ground (pp. 75-90). London: Palgrave Macmillan.

Aizawa, K., \& Gillett, C. (2009). The (multiple) realization of psychological and other properties in the sciences. Mind and Language, 24, 181-208.

Aizawa, K., \& Gillett, C. (2011). The autonomy of psychology in the age of neuroscience. In P. McKay Illary, F. Russo, \& J. Williamson (Eds.), Causality in the sciences (pp. 202-223). Oxford: Oxford University Press. 
Aizawa, K., \& Gillett, C. (2016). Vertical relations in science, philosophy, and the world: Understanding the new debates over verticality. In K. Aizawa \& C. Gillett (Eds.), Scientific composition and metaphysical ground (pp. 1-38). London: Palgrave Macmillan.

Anderson, M. L. (2010). Neural reuse: A fundamental organizational principle of the brain. Behavioral and Brain Sciences, 33, 245-313.

Assis, L. C. S., \& Brigandt, I. (2009). Homology: Homeostatic property cluster kinds in systematics and evolution. Evolutionary Biology, 36, 248-255.

Austin, C. J. (2016). The ontology of organisms: Mechanistic modules or patterned processes? Biology and Philosophy, 31, 639-662.

Austin, C. J., \& Nuño de la Rosa, L. (2018). Dispositional properties in evo-devo. In L. Nuño de la Rosa \& G. Müller (Eds.), Evolutionary Developmental Biology. Berlin: Springer. https://doi. org/10.1007/978-3-319-33038-9_64-1.

Balari, S., \& Lorenzo, G. (2013). Computational phenotypes. Towards an evolutionary developmental biolingustics. Oxford: Oxford University Press.

Balari, S., \& Lorenzo, G. (2015). Ahistorical homology and multiple realizability. Philosophical Psychology, 28, 881-902.

Balari, S., \& Lorenzo, G. (2018). The internal, the external and the hybrid: The state of the art and a new characterization of language as a natural object. Glossa. https://doi.org/10.5334/gjgl.330.

Barlow, M., \& Ferguson, C. (Eds.). (1988). Agreement in natural language: Approaches, theories, descriptions. Stanford, CA: CSLI Publications.

Bates, E., Brethenton, I., \& Snyder, L. (1988). From first words to grammar: Individual differences and dissociable mechanisms. New York: Cambridge University Press.

Bateson, P., \& Gluckman, P. (2011). Plasticity, robustness, development and evolution. Cambridge: Cambridge University Press.

Baysan, U. (2015). Realization relations in metaphysics. Minds and Machines, 25, 247-260.

Bechtel, W., \& Mundale, J. (1999). Multiple realizability revisited: Linking cognitive and mental states. Philosophy of Science, 66, 174-207.

Bergeron, V. (2007). Anatomical and functional modularity in cognitive science: Shifting the focus. Philosophical Psychology, 20, 175-195.

Bickle, J. (2003). Philosophy and neuroscience: A ruthlessly reductive account. Boston, MA: Kluwer.

Bickle, J. (2016). Multiple realizability. In E. N. Zalta (Ed.), The stanford encyclopedia of philosophy (Spring 2016 Edition). Resource document. https://plato.stanford.edu/archives/spr2016/entries/ multiple-realizability/. Accessed 15 July 2018.

Blake, B. J. (2001). Case (2nd ed.). Cambridge: Cambridge University Press.

Block, N., \& Fodor, J. A. (1972). What psychological states are not. The Philosophical Review, 81, $159-181$.

Bock, W. J., \& von Wahlert, G. (1965). Adaptation and the form-function complex. Evolution, 19, 269-299.

Boyd, R. N. (1980). Materialism without reductionism: What physicalism does not entail. In N. Block (Ed.), Readings in the philosophy of psychology (Vol. 1, pp. 67-106). Cambridge, MA: Harvard University Press.

Boyd, R. N. (1991). Realism, anti-foundationalism and the enthusiasm for natural kinds. Philosophical Studies, 61, 127-148.

Boyd, R. N. (1999). Kinds, complexity and multiple realization. Philosophical Studies, 95, 67-98.

Brigandt, I. (2009). Natural kinds in evolution and systematics: Metaphysical and epistemological considerations. Acta Biotheoretica, 57, 77-97.

Brigandt, I. (2013). Systems biology and the integration of mechanistic explanation and matehamatical explanation. Studies in History and Philosophy of Biological and Biomedical Sciences, 44, $477-492$.

Brigandt, I. (2015). Evolutionary developmental biology and the limits of philosophical accounts of mechanistic explanation. In P.-A. Braillard \& C. Malaterre (Eds.), Explanation in biology. An enquiry into the diversity of explanatory patterns in the life sciences (pp. 135-173). Heidelberg: Springer.

Brigandt, I. (2017). Typology and natural kinds in evo-devo. In L. Nuño de la Rosa \& G. Müller (Eds.), Evolutionary developmental biology. Berlin: Springer. https://doi.org/10.1007/978-3-319-33038 $-9 \_100-1$.

Brigandt, I., \& Love, A. C. (2010). Evolutionary novelty and the evo-devo synthesis: Field notes. Evolutionary Biology, 37, 93-99. 
Brigandt, I., \& Love, A. C. (2012). Conceptualizing evolutionary novelty: Moving beyond definitional debates. Journal of Experimental Zoology (Molecular and Developmental Evolution), 318B, $417-427$.

Brown, R. L. (2015). Why development matters. Biology and Philosophy, 30, 889-899.

Chiu, L., \& Gilbert, S. F. (2015). The birth of the holobiont: Multi-species birthing through mutual scaffolding and niche construction. Biosemiotics, 8, 191-210.

Chomsky, N. (1995). The minimalist program. Cambridge, MA: The MIT Press.

Chomsky, N. (2000). New horizons in the study of language and mind. Cambridge: Cambridge University Press.

Clahsen, H. (1986). Verb inflections in German child language: Acquisition of agreement markings and the functions they encode. Linguistics, 24, 79-121.

Clahsen, H., Bartke, S., \& Göllner, S. (1997). Formal features in impaired grammars: A comparison of English and German SLI children. Journal of Neurolinguistics, 10, 151-171.

Clahsen, H., \& Hansen, D. (1997). The grammatical agreement deficit in specific language impairment: Evidence from therapy experiments. In M. Gopnik (Ed.), The inheritance and innateness of grammars (pp. 141-160). Oxford: Oxford University Press.

Corbett, G. G. (2009). Agreement. Cambridge: Cambridge University Press.

Couch, M. B. (2004). Discussion: A defense of Bechtel and Mundale. Philosophy of Science, 71, 198-204.

Couch, M. B. (2009). Multiple realization in comparative perspective. Biology and Philosophy, 24, $505-519$.

Craver, C. F. (2001). Role functions, mechanisms, and hierarchy. Philosophy of Science, 68, 55-74.

Craver, C. F. (2007). Explaining the brain. Mechanisms and the mosaic unity of neuroscience. Oxford: Oxford University Press.

Cummins, R. (1975). Functional analysis. The Journal of Philosophy, 72, 741-760.

Cummins, R. (1983). The nature of psychological explanation. Cambridge, MA: The MIT Press.

Cummins, R. (2002). Neo-teleology. In A. Ariew, R. Cummins, \& M. Perlman (Eds.), Functions. New essays in the philosophy of psychology and biology (pp. 157-172). Oxford: Oxford University Press.

Dennett, D. C. (1991). Real patterns. The Journal of Philosophy, 88, 27-51.

Dupré, J., \& Nicholson, D. J. (2018). A manifesto for a processual philosophy of biology. In D. J. Nicholson \& J. Dupré (Eds.), Everything flows. Towards a processual philosophy of biology (pp. 3-45). Oxford: Oxford University Press.

Fodor, J. A. (1965). Explanations in psychology. In M. Black (Ed.), Philosophy in America (pp. 161179). Ithaca, NY: Cornell University Press.

Fodor, J. A. (1968). Psychological explanation: An introduction to the philosophy of psychology. New York: Random House.

Fodor, J. A. (1974). Special sciences (Or: The disunity of science as a working hypothesis). Synthese, $28,77-115$.

Fodor, J. A. (1975). The language of thought. Cambridge, MA: Harvard University Press.

Gilbert, S. F. (2000). Diachronic biology meets evo-devo: C. H. Waddington's approach to evolutionary developmental biology. American Zoologist, 40, 729-737.

Gilbert, S. F. (2001). Ecological developmental biology: Developmental biology meets the real world. Developmental Biology, 233, 1-12.

Gilbert, S. F. (2014). Developmental Biology (10th ed.). Sunderland, MA: Sinauer.

Gilbert, S. F., \& Epel, D. (2015). Ecological developmental biology. The environmental regulation of development, health, and evolution (2nd ed.). Sunderland, MA: Sinauer.

Gillett, C. (2002). The dimensions of realization: A critique of the standard view. Analysis, 62, $316-323$.

Gillett, C. (2003). The metaphysics of realization, multiple realizability, and the special sciences. The Journal of Philosophy, 100, 591-603.

Gillett, C. (2007). Understanding the new reductionism: The metaphysics of science and compositional reduction. The Journal of Philosophy, 104, 193-216.

Gillett, C. (2016). The metaphysics of nature, science, and the rules of engagement. In K. Aizawa \& C. Gillett (Eds.), Scientific composition and metaphysical ground (pp. 205-247). London: Palgrave Macmillan.

Giorgi, F., \& Bruni, L. E. (2015). Developmental scaffolding. Biosemiotics, 8, 173-189.

Glennan, S. (2017). The new mechanical philosophy. Oxford: Oxford University Press. 
Gottlieb, G. (2007). Probabilistic epigenesis. Developmental Science, 10, 1-11.

Griesemer, J. R. (2000). Development, culture, and the units of inheritance. Philosophy of Science, 67, S348-S368.

Griesemer, J. R. (2014a). Reproduction and the scaffolded development of hybrids. In L. Caporael, J. R. Griesemer, \& W. C. Wimsatt (Eds.), Developing scaffolds in evolution, culture, and cognition (pp. 23-55). Cambridge, MA: The MIT Press.

Griesemer, J. R. (2014b). Reproduction and scaffolded development processes: An integrated evolutionary perspective. In A. Minelli \& T. Pradeu (Eds.), Towards a theory of development (pp. 183-202). Oxford: Oxford University Press.

Haig, D. (2015). Sameness, novelty, and nominal kinds. Biology and Philosophy, 30, 857-872.

Jaeger, J., \& Monk, N. (2015). Everything flows. A process perspective of life. EMBO Reports, 16, 1064-1067.

Joshi, A. K. (1985). Tree adjoining grammars: How much context-sensitivity is required to provide reasonable structural descriptions? In D. R. Dowty, L. Karttunen, \& A. M. Zwicky (Eds.), Natural language parsing: Psychological, computational, and theoretical perspectives (pp. 206-250). Cambridge: Cambridge University Press.

Kauffman, S.A. (1970). Articulation of parts explanation I biology and the rational search for them. In Proceedings of the biennial meeting of the philosophy of science association. Boston Studies in the Philosophy of Science (Vol. 8, pp. 257-272).

Kauffman, S. A. (1993). The origins of order. self-organization and selection in evolution. Oxford: Oxford University Press.

Kim, J. (1998). Mind in a physical world. An essay on the mind-body problem and mental causation. Cambridge, MA: The MIT Press.

Kim, J. (2005). Physicalism, or something near enough. Princeton, NJ: Princeton University Press.

Kim, J. (2010). Thoughts on Sydney shoemaker's. Physical Realization Philosophical Studies, 148, $101-112$.

Klein, C. (2008). An ideal solution to disputes about multiply realized kinds. Philosophical Studies, 140, 161-177.

Klein, C. (2013). Multiple realizability and the semantic view of theories. Philosophical Studies, 163, 683-695.

Koonin, E. V. (2005). Orthologs, paralogs, and evolutionary genomics. Annual Review of Genetics, 39, 309-338.

Ladyman, J., Ross, D., Spurrett, D., \& Collier, J. (2007). Every thing must go: Metaphysics naturalized. Oxford: Oxford University Press.

Lenneberg, E. H. (1967). Biological foundations of language. New York: Wiley.

Lorenzo, G. (2018). Long-distance paradox and the hybrid nature of language. In Biosemiotics. https:// doi.org/10.1007/s12304-018-9331-1

Love, A. C. (2007). Functional homology and homology of function: Biological concepts and philosophical consequences. Biology and Philosophy, 22, 691-708.

Love, A. C. (2015). ChINs, swarms, and variational modalities: Concepts in the service of an evolutionary research program. Biology and Philosophy, 30, 873-888.

Love, A. C. (2018). Developmental mechanisms. In S. Glennan \& P. Illari (Eds.), The Routledge handbook of mechanisms and mechanical philosophy (pp. 332-347). London: Routledge.

Machamer, P., Darden, L., \& Craver, C. F. (2000). Thinking about mechanisms. Philosophy of Science, 67, 1-25.

Mahner, M., \& Bunge, M. (2001). Function and functionalism: A synthetic perspective. Philosophy of Science, 68, 75-94.

Marchman, V., \& Bates, E. (1994). Continuity in lexical and morphological development: A test of the critical mass hypothesis. Journal of Child Language, 21, 339-366.

Marchman, V., \& Thal, D. (2005). Words and grammar. In M. Tomasello \& D. Slobin (Eds.), Beyond nurture-nature: essays in honor of Elizabeth Bates (pp. 141-164). Mahwah, NJ: Erlbaum.

Maynard-Smith, J. (1970). Natural selection and the concept of a protein space. Nature, 255, 563-564.

McGregor, K., Sheng, L., \& Smith, B. (2005). The precocious two-year-old: Status of the lexicon and links to the grammar. Journal of Child Language, 32, 563-585.

Melnyk, A. (2003). A physicalist manifesto. Thoroughly modern materialism. Cambridge: Caambridge University Press.

Millikan, R. G. (1984). Language, thought, and other biological categories. New foundations for realism. Cambridge, MA: The MIT Press. 
Millikan, R. G. (1999). Historical kinds and the "special sciences". Philosophical Studies, 95, 45-65.

Minelli, A. (2003). The development of animal form. Cambridge: Cambridge University Press.

Minelli, A. (2011). Development, an open-ended segment of life. Biological Theory, 6, 4-15.

Moreno, Á., \& Mossio, M. (2015). Biological autonomy: A philosophical and theoretical enquiry. Dordrecht: Springer.

Neander, K. (1991). The teleological notion of 'function'. Australasian Journal of Philosophy, 69, 454-468.

Nicholson, D. J. (2013). Organisms $\neq$ machines. Studies in History and Philosophy of Biological and Biomedical Sciences, 44, 669-678.

Nicholson, D. J. (2014). The machine conception of the organism in development and evolution: A critical analysis. Studies in History and Philosophy of Biological and Biomedical Sciences, 48, 162-174.

Nicholson, D. J. (2018). Reconceptualizing the organism. From complex machine to flowing stream. In D. J. Nicholson \& J. Dupré (Eds.), Everything flows. Towards a processual philosophy of biology (pp. 139-168). Oxford: Oxford University Press.

Nicholson, D. J., \& Gawne, R. (2015). Neither logical empiricism nor vitalism, but organicism: What the philosophy of biology was. History and Philosophy of the Life Sciences, 37, 345-381.

Oppenheim, R. W. (1981). Ontogenetic adaptations and retrogressive processes in the development of the nervous system and behaviour: A neuroembriological perspective. In K. J. Connolly \& H. F. R. Prechtl (Eds.), Maturation and development: Biological and psychological perspectives (pp. 73-109). Philadelphia, PA: Lippincott.

Oppenheim, R. W. (1984). Ontogenetic adaptations in neural and behavioural development: Toward a more 'ecological' developmental psychobiology. In H. F. R. Prechtl (Ed.), Continuity of neural functions from prenatal to postnatal life (pp. 16-30). Philadelphia, PA: Lippincott.

Oppenheim, P., \& Putnam, H. (1958). Unity of Science as a working hypothesis. In H. Feigl, M. Scriven, \& G. Maxwell (Eds.), Concepts, theories, and the mind-body problem. Minnesota Studies in the Philosophy of Science (Vol. 2, pp. 3-36). Minneapolis, MN: University of Minnesota Press.

Owen, R. (1848). On the archetype and homologies of the vertebrate skeleton. London: John Van Voorst.

Patterson, D. A., \& Hennessy, J. L. (2017). Computer organization and design: The hardware/software interface (ARM ed.). Cambridge, MA: Morgan Kaufmann.

Peterson, E. L. (2011). The excluded philosophy of evo-devo? Revisiting C. H. Waddinton's failed attempt to embed Alfred North Whitehead's 'organicism' in evolutionary biology. History and Philosophy of the Life Sciences, 33, 301-320.

Piccinini, G., \& Craver, C. F. (2011). Integrating psychology and neuroscience: Functional analyses as mechanism sketches. Synthese, 183, 283-311.

Poland, J. (1994). Physicalism: The philosophical foundations. Oxford: Oxford University Press.

Polger, T. W. (2004). Natural minds. Cambridge, MA: The MIT Press.

Polger, T. W. (2007). Realization and the metaphysics of mind. Australasian Journal of Philosophy, 85, 233-259.

Polger, T. W. (2010). Mechanisms and explanatory realization relations. Synthese, 177, 193-212.

Polger, T. W., \& Shapiro, L. A. (2016). The multiple realization book. Oxford: Oxford University Press.

Pradeu, T. (2018). Genidentity and biological processes. In D. J. Nicholson \& J. Dupré (Eds.), Everything flows. Towards a processual philosophy of biology (pp. 96-112). Oxford: Oxford University Press.

Putnam, H. (1975a). Minds and machines. In Mind, language and reality: Philosophical papers (Vol. 2, pp. 362-385). New York: Cambridge University Press.

Putnam, H. (1975b). The mental life of some machines. In Mind, language and reality: Philosophical papers (Vol. 2, pp. 408-428). New York: Cambridge University Press.

Putnam, H. (1975c). The nature of mental states. In Mind, language and reality: Philosophical papers (Vol. 2, pp. 429-440). New York: Cambridge University Press.

Ross, D. (2000). Rainforest realism: A Dennettian theory of existence. In D. Ross, A. Brook, \& D. Thompson (Eds.), Dennett's philosophy: A comprehensive assessment (pp. 147-168). Cambridge, MA: The MIT Press.

Ross, D., \& Spurrett, D. (2004). What to say to a skeptical metaphysician: A defense manual for cognitive and behavioral scientists. Behavioral and Brain Sciences, 27, 603-647.

Salmon, W. C. (1984). Scientific explanation and the causal structure of the world. Princeton, NJ: Princeton University Press.

Shapiro, L. A. (2000). Multiple realizations. The Journal of Philosophy, 97, 635-654.

Shapiro, L. A. (2004). The mind incarnate. Cambridge, MA: The MIT Press. 
Shoemaker, S. (2007). Physical realization. Oxford: Oxford University Press.

Smolin, L. (2001). Three roads to quantum gravity. New York: Basic Books.

Sultan, S. (2007). Development in context: The timely emergence of eco-devo. Trends in Ecology \& Evolution, 22, 575-582.

Sultan, S. (2015). Organism and environment. Ecological development, niche construction, and adaptation. Oxford: Oxford University Press.

Sultan, S. (2017). Eco-evo-devo. In L. Nuño de la Rosa, \& G. B. Müller (Eds.), Evolutionary developmental biology. https://doi.org/10.1007/978-3-319-33038-9_42-1.

von Bertalanffy, L. (1952). Problems of life. An evaluation of modern biological thought. New York: Wiley.

von Dassow, G., \& Munro, E. (1999). Modularity in animal development and evolution: Elements for a conceptual framework for EvoDevo. Journal of Experimental Zoology (Mol Dev Evol), 285, $307-325$.

Waddingotn, C. H. (1969). The practical consequences of metaphysical beliefs on a biologist's work: An autobiographical note. In C. H. Waddington (Ed.), Sketching theoretical biology: Toward a theoretical biology (Vol. 2, pp. 72-81). New Brunswick, NJ: AldineTransaction.

Waddington, C. H. (1957). The strategy of the genes. A discussion of some aspects of theoretical biology. London: George Allen \& Unwin.

Waddington, C. H. (1968). Towards a theoretical biology. Nature, 218, 525-527.

Wagner, G. P. (1989a). The biological homology concept. Annual Review of Ecology and Systematics, 20, 51-69.

Wagner, G. P. (1989b). The origin of morphological characters and the biological basis of homology. Evolution, 43, 1157-1171.

Wagner, G. P. (2007). The developmental genetics of homology. Nature Reviews Genetics, 8, 473-479.

Wagner, A. (2011). The origins of evolutionary innovations. A theory of transformative change in living systems. Oxford: Oxford University Press.

Wagner, G. P. (2014). Homology, genes, and evolutionary innovation. Princeton, NJ: Princeton University Press.

Wagner, G. P. (2015). Homology and the evolutionary process: Reply to Haig, Love and Brown on "Homology, Genes and Evolutionary Innovation". Biology and Philosophy, 30, 901-912.

Wilson, R. A., Barker, M. J., \& Brigandt, I. (2007). When traditional essentialism fails: Biological natural kinds. Philosophical Topics, 35, 189-215.

Wilson, R. A., \& Craver, C. F. (2007). Realization: metaphysical and scientific perspectives. In P. Thagard (Ed.), Handbook of the philosophy of science. Philosophy of psychology and cognitive science (pp. 81-104). Amsterdam: Elsevier.

Wimsatt, W. C. (1976). Reductionism, levels of organization, and the Mind-Body problem. In G. G. Globus, G. Maxwell, \& I. Savodnik (Eds.), Consciousness and the brain. A Scientific and philosophical inquiry (pp. 199-267). New York: Plenum Press.

Wimsatt, W. C. (1981). Robustness, reliability, and overdetermination. In M. B. Brewer \& B. E. Collins (Eds.), Scientific inquiry in the social sciences: A volume in honor of Donald T. Campbell (pp. 123-162). San Francisco, CA: Jossey-Bass.

Wimsatt, W. C. (1994). The ontology of complex systems: Levels of organization, perspectives, and causal thickets. Canadian Journal of Philosophy, Supplementary, 20, 207-274.

Wimsatt, W. C. (2002). Functional organization, analogy, and inference. In A. Ariew, R. Cummins, \& M. Perlman (Eds.), Functions. New essays in the philosophy of psychology and biology (pp. 173-221). Oxford: Oxford University Press.

Wimsatt, W. C. (2007). Re-engineering philosophy for limited beings. Piecewise approximations to reality. Cambridge, MA: Harvard University Press.

Winograd, T., \& Flores, F. (1986). Understanding computers and cognition. A new foundation for design. Reading, MA: Addison-Wesley.

Wouters, A. G. (2003). Four notions of biological function. Studies in History and Philosophy of Biological and Biomedical Sciences, 34, 633-668.

Publisher's Note Springer Nature remains neutral with regard to jurisdictional claims in published maps and institutional affiliations. 